\title{
Study on sedimentary facies characteristics of Xujiahe Formation in Sichuan Basin
}

\author{
WANG Zhiguo ${ }^{* 1}$ \\ ${ }^{1}$ Exploration and Development Research Institute of Daqing Oil Field Co. Ltd, Daqing City, Heilongjiang Province, 163712,China
}

\begin{abstract}
Sedimentary facies is the summation of all primary sedimentary features in a sedimentary unit, which is the product of sedimentation in a specific environment. It emphasizes the material performance of sediment formation conditions, including mineralogy, petrology, paleontology, geochemistry and geophysics. Therefore, it has unique sedimentary features in this environment. In this paper, the types and units of sedimentary facies which can reflect the basic characteristics and geometry of sedimentary system are established, and based on the comprehensive analysis of rock types, lithological assemblages, sedimentary structures, palaeontological assemblages and section structures, the sedimentary facies types of Xujiahe formation of Upper Triassic in the study area mainly include semi-arid flooded basin facies, delta facies, beach bar-lagoon system and lake facies, among which delta facies and beach bar-lagoon system are the main sedimentary facies types. Because sedimentary facies is the historical product of basin formation, evolution and extinction, it can not only reflect the formation conditions, temporal and spatial distribution and evolution law of related strata and rock types, but also be the basis for analyzing the nature and structural background of sedimentary basin. At the same time, the analysis of sedimentary facies is of great significance for understanding and analyzing the evolution history of basin and guiding the exploration and development of related oil and gas resources.
\end{abstract}

\section{Introduction}

Sichuan Basin is a multicycle sedimentary basin on the Yangtze block. From Sinian to Middle Triassic, it has been a stable large depression area. The Indosinian tectonic compression at the end of Middle Triassic made the surrounding island chain strongly thrust to form a mountain system. In the middle and late late Late Triassic, Xichang, Panzhihua and Central Yunnan areas transformed into foreland basins, Thus, a large coal bearing sedimentary basin, the upper Yangtze sedimentary basin in the Late Triassic, is formed by connecting it with the "Sichuan Basin", covering an area of $10 \times 10^{4} \mathrm{~km}^{2}$. The present "Sichuan Basin" is only a part of the upper Yangtze sedimentary basin in the Late Triassic. During the sedimentary period of Xujiahe formation, Sichuan Basin was a large bay connected with the ocean only in the southwest. During the sedimentary period of Xujiahe formation, the basin experienced three ups and downs, forming a sandwich structure between large open flow delta deposits and deep lake deposits. The first, third and fifth members of the Xujiahe formation are developed with coal shale deposits. The second, fourth and sixth members of the Xujiahe formation are sandstone and conglomerate ${ }^{[1][2][3]}$.

\section{Review of sedimentary facies markers}

In the process of studying the depositional system of the study area, first of all, a detailed analysis of the surface profile of the study area, combined with the actual field observation of the adjacent areas studied by predecessors, and a comprehensive study of the drilling data (core data, logging data, core analysis data, etc.) were carried out to master the sedimentological information reflected by various data, Based on the principles of sedimentology and well logging geology, sedimentary facies types and facies units reflecting the basic characteristics and geometry of sedimentary system are established ${ }^{[4][5]}$.

The main identification marks of sedimentary facies and subfacies in the study area are: color characteristics, structural characteristics, sedimentary structure, logging curve characteristics, paleontological fossils, etc.

\subsection{Color mark}

The color of rock, especially the primary color of mudstone, can be used as a direct indicator to judge the climate condition, water medium oxidation-reduction conditions and the quality of source rock. When the primary color is involved in the naming of rocks, the paleoclimate and the physical and chemical conditions of fluid medium of related rocks have been given

\footnotetext{
${ }^{*}$ Corresponding author: 47310372@qq.com
} 
information. From the primary color change characteristics of mud and shale in Xujiahe formation of Upper Triassic, lower Jurassic, middle and Upper Jurassic, it reflects that northeast Sichuan has the characteristics of warm and humid $\left(T_{3} \mathrm{x}\right)$, The paleoclimate changes from hot and semi-arid $\left(\mathrm{j}_{1} \mathrm{z}-\mathrm{j}_{1-2} \mathrm{l}\right)$ to hot and arid $\left(\mathrm{j}_{2} \mathrm{Xs}-\mathrm{j}_{3} \mathrm{p}\right)$, and the corresponding fluid medium conditions and physicochemical properties of the sedimentary basin also change from reduction $\left(T_{3} x\right)$, weak reduction $\left(j_{1} z-j_{1-2} l\right)$ to oxidation $\left(\mathrm{j}_{2} \mathrm{xs}-\mathrm{j}_{3} \mathrm{p}\right)$.

\subsection{Rock structure mark}

The grain size of rock can reflect the hydrodynamic conditions of sedimentary environment and the distance of debris transportation. The grain size distribution can be used as one of the means to judge the sedimentary environment. The structural characteristics of rocks are the direct reflection of the medium conditions during deposition. The sediments formed under different medium conditions have different structural characteristics. Even if they are formed under the same medium conditions, the sediment particles will change from coarse to fine as the hydrodynamic conditions change from strong to weak. In addition, the speed of deposition and the time of transformation are also reflected in the sediment structure. The fourth to sixth members of Upper Triassic Xujiahe Formation in shiguansi section of Wanyuan around the study area are characterized by a large number of conglomerate accumulated in the fan, with poor sorting and roundness.

\subsection{Sedimentary structure mark}

Sedimentary structure is one of the important characteristics of sedimentary rocks. They are macroscopic characteristics caused by the heterogeneity of composition, structure and color of sediments. Its scale is generally large, and it can be directly observed and described in field outcrops and cores. Among them, primary sedimentary structures refer to those structures formed during or shortly after sediment deposition and before consolidation. They can provide information about the properties of sedimentary media and energy conditions during the depositional period. As the development of sedimentary structure is directly related to sedimentary velocity, water flow action mode and medium condition, the primary sedimentary structure and its combination or sequence have become the most important marks for distinguishing sedimentary environment and dividing sedimentary facies, subfacies and microfacies. The primary sedimentary structures in the study area mainly include bedding structure and bedding structure.

The biological fossils in the sediments or strata can not only be used to identify the geological age of the strata, divide and correlate the strata, but also be one of the important marks for the analysis of sedimentary environment. At present, the application of paleontological markers mainly plays an important role in the division of large environment, such as the emergence of a large number of plant fossils, especially plant rhizomes, carbonaceous mudstone and coal seams, reflecting the continental environment.

The development of the bottom scour structure is related to the sudden change of hydrodynamic conditions from weak to strong. Generally, the hydrodynamic conditions of the sedimentary environment above the scour surface are significantly enhanced compared with those below. Therefore, the sediments accumulated before the development of the scour surface are subject to different degrees of undercutting erosion during the process of bottom scour, The bottom scour surface is characterized by an uneven scour surface and a lithologic mutation surface. The rock grain size in the upper part of the scour surface is obviously coarser than that in the lower part, or contains mud and gravel from the underlying layer. Therefore, the erosion surface can represent a different degree of erosion discontinuity, which is usually developed in the sedimentary environment with strong and weak hydrodynamic conditions and frequent changes, such as river and delta.

Bedding is one of the most important appearance features of sediments or sedimentary rocks, and it is also the main sign that sedimentary rocks are different from magmatic rocks and some metamorphic rocks. Bedding is a layered structure formed by the change of rock properties along the direction of sediment accumulation (material composition, color, structure, etc.). It can be further divided into cross bedding, wavy bedding, grain order bedding, parallel bedding, horizontal bedding and composite bedding (wavy bedding, lenticular bedding, etc.). All kinds of bedding are very developed and colorful in the study area.

\subsection{Paleontological mark}

The biological fossils in the sediments or strata can not only be used to identify the geological age of the strata, divide and correlate the strata, but also be one of the important marks for the analysis of sedimentary environment. At present, the application of paleontological markers mainly plays an important role in the division of large environment, such as the emergence of a large number of plant fossils, especially plant rhizomes, carbonaceous mudstone and coal seams, reflecting the continental environment. There are plant stem fossils and minable coal seams in fluvial strata of Xujiahe formation of Upper Triassic in the study area.

\section{Sedimentary facies type}

According to the comprehensive analysis of rock type, lithologic association, sedimentary structure, paleontological Association and section structure, the following sedimentary facies types are mainly developed in Xujiahe Formation Jurassic system of Upper Triassic in the study area.

\subsection{Semi-arid flooded basin facies}

The flood basin facies in the semi-arid area mentioned in this study mainly refers to fluvial facies, which is widely 
distributed in the upper Triassic to Jurassic strata in the study area, mainly in fluvial basin and fluvial basin. It has obvious vertical zonation and plane zonation distribution characteristics, and is obviously controlled by paleotopography, mainly as follows: in the upper reaches or the lower part of the profile, the fluvial basin is mainly developed, while in the lower reaches or the upper part of the profile, the fluvial basin is mainly developed; In plane, the fluvial basin is mainly distributed near the source area at the edge of the basin, while the fluvial basin is mainly developed at the transitional position from the edge of the basin to the center of the basin. Among them, the microfacies sandbodies of the central beach in the fluvial basin and the marginal beach in the fluvial basin are one of the important reservoir sandbodies in the study area, while the microfacies of the inter River depression, especially the mire microfacies of the marsh inter River depression, mud and shale are the important source rocks and effective regional cap rocks in the study area.

\subsection{Delta facies}

Delta is a large cone-shaped sedimentary system formed at the confluence of rivers and lakes (or basins), which can be divided into the top (also called delta plain subfacies), progradars (also known as delta front slope subfacies), and bottom (also known as pre delta subfacies). The continental lake delta can be divided into Braided River Delta, meandering river delta and net River Delta according to the river type controlling the sedimentation of the delta. Braided river delta facies in the study area are mainly distributed in Xujiahe formation, in which the sand bodies of Xuhe section 2 and xusi are thick, and the mud content is small, mainly composed of sand, and the mud interlayer in the channel sand body is rarely seen. Generally, a large set of sandstone appears, which is formed by multi-stage River superimposition. Therefore, we think it is braided river delta, The main reason for this feature is that the shallow flow of braided river is fast, the flow is unstable, and the lateral migration of the channel is frequent, which results in the fine matter deposited on the top of the river channel being washed away by the new stage of river channel before consolidation, and the accumulation of coarse-grained material. The continuous vertical stacking of the river leads to the characteristics of large deposition thickness and less fine-grained material content in braided river.

The origin of braided river delta is related to the fact that the river from the mountain pass still flows into the lake as braided river after passing through the narrow fan delta plain of alluvial fan. Its grain size is obviously coarser than that of Meandering River Delta. It is a kind of near source coarse clastic delta developed adjacent to alluvial fan, The braided river delta is further divided into two subfacies: plain and front. At the end of the braided river delta front, with the disappearance of underwater braided distributary channel and the formation of estuary bar distal bar, it gradually enters into the pre delta subfacies. The corresponding subfacies can be further subdivided into several microfacies. The braided river delta plain in this study area is mainly developed in the fourth member of Xujiahe formation, and also in the middle and upper part of the second member of Xujiahe Formation in some areas. In addition, braided river delta plain braided channel sedimentary environment is also developed at the bottom of the first member of Xujiahe Formation in lixiya section, with coarse lithology, mainly medium coarse sandstone, intercalated with breccia and gravelly sandstone. The main reason for this difference is that the lixiya section is closer to the provenance, closer to the edge of the basin, with higher terrain and no sea water coming from it. The braided river delta front is mainly developed in the second member of Xujiahe formation. The former Braided River Delta is not developed in this study area, and the lithology is mainly silty mudstone.

\subsection{Beach bar-lagoon system}

This kind of system is mainly marine terrestrial interaction. Marine terrestrial interaction has its own characteristics. In the transition area between the ocean and the land, on the one hand, the sea water continuously scours the coastline to make the sediment become finer and purer. On the other hand, the land direction continuously provides a large number of material sources. After crossing the coastline, it is blocked by the sea water and then deposited to accept the seawater transformation. When the wave action is stronger than the river action, the land river channel is constantly affected by the tide, and then widens; When the fluvial action is strong, the channel extends to the sea continuously, and the sedimentary body has the characteristics of progradation. The transitional facies between sea and land in this area only occurs in the lower Jurassic (Fig. 1).

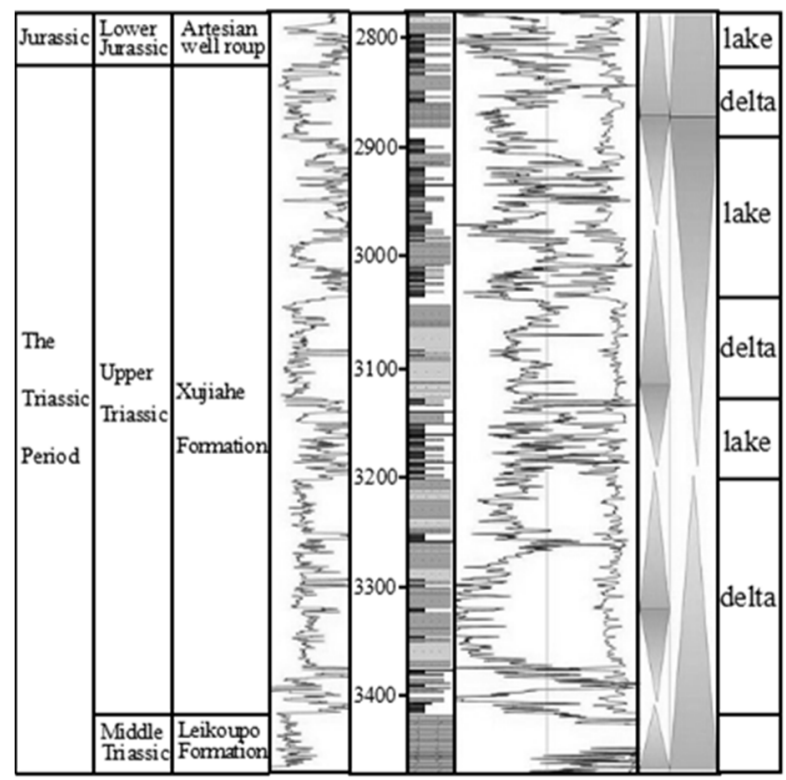

Fig. 1. Sedimentary characteristics of Upper Triassic beach bar lagoon system.

The main lithologic characteristics are fine siltstone and argillaceous sediments with good roundness and sorting. It includes lenticular bedding, vein bedding, wavy bedding and pinnate cross bedding, as well as plate and 
trough cross bedding formed by river action.

\subsection{Lake facies}

Lakes are relatively low-lying areas on the continent where water flows. The lake facies of Xujiahe Formation in the foreland basin of Northeast Sichuan Province is developed, mainly seen in xusan, Xuwu and Xu2 "belt Zi" of Lower Jurassic and Xujiahe formation. According to the water depth change determined by various facies signs and combined with the actual situation of the study area, it is divided into a sub phase of shore shallow lake.

The waterfront subfacies are located between the flood shoreline and the dry water shoreline, that is, the water depth decreases to the area where the waves break and form a strong wave, and the scour and backflow wash the lake bank repeatedly. Therefore, the hydrodynamic force of the lakeside environment can be strong (in flood level), weak (in the dry water level), and it is often oxidation environment, which is not suitable for biological survival. The sub facies of shore shallow lake is characterized by frequent interbedding of sand and mud, with good sand mud differentiation and obvious stratification. However, the lateral change of lithology and thickness is fast and the continuity is poor. The development of sand bodies in each part is different, so the characteristics of logging curve and seismic facies also change greatly.

\section{Main sedimentary assemblage facies model}

On the discussion of sedimentary system of Xujiahe formation, this paper considers that in addition to delta facies sand (Fig. 2), beach bar lagoon facies is also the main sedimentary facies type of Xujiahe Formation ${ }^{[6]}$ (Fig. $3)$. The formation process of the delta system is that the river transported materials from the source to the sink, unloaded near the estuary and accumulated continuously; The construction process of beach bar lagoon system is a process in which the detrital materials from various sources, such as river unloading materials, are repeatedly washed and transformed by wind waves and tides, and redistributed under the action of wind waves, tides and coastal currents. The former is a vertical geological process, while the latter is a horizontal geological process. In the geological process chain of "initial unloading transformation redistribution", the delta system and the beach bar system are at two ends, and the initial unloading material is the main body of the formation, namely the delta system; There are also a series of transition types between the two different systems.

\section{Conclusion and understanding}

Through research and analysis, sedimentary facies types and facies units are established, which can reflect the basic characteristics and geometric morphology of sedimentary system. The main identification marks are: color characteristics, structural characteristics, sedimentary structure, logging curve characteristics, paleontological fossils, etc.

According to the comprehensive analysis of rock type, lithologic association, sedimentary structure, paleontological Association and section structure, the sedimentary facies types of Xujiahe Formation in the study area mainly include flood basin facies, delta facies, beach bar lagoon system and lake facies in the semi-arid area, in which delta facies and beach bar lagoon system are the main sedimentary facies types.

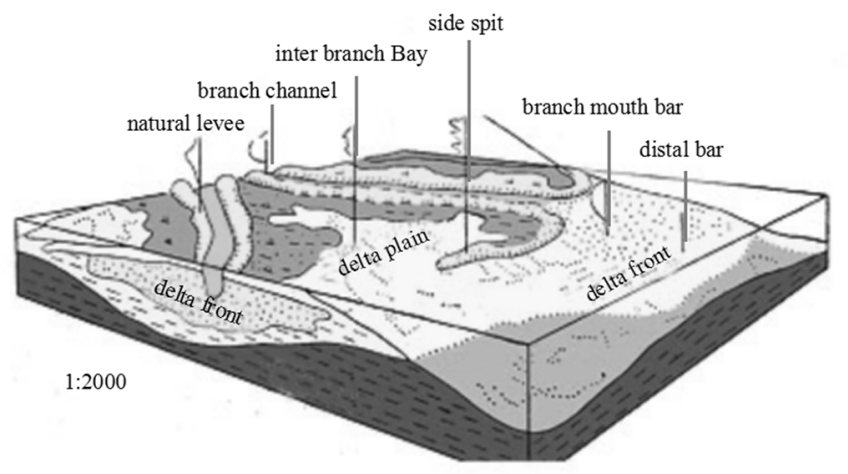

Fig. 2. Schematic diagram of delta system.

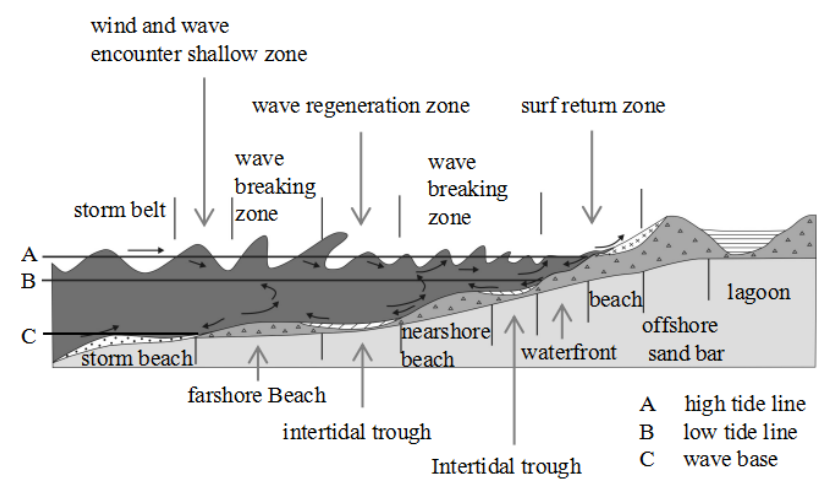

Fig. 3. Section diagram of beach bar-lagoon system.

\section{References}

1. Zhao Xiafei, Zhang Wenlin. A re-discussion on the origins of tidal deposits in the Xujiahe Formation of the Sichuan Basin:Further evidences and sequence analysis (Chinese:Natural Gas Industry) 2011, 31 (9) : p 25-30

2. LI Guoyu, CHEN Qilin, BAI Yunlai, etc. Marine sediment: The future expectation of China ' $\mathrm{s}$ petroleum industry (Chinese:Northwest Oil \& Gas Exploration) 2014, 26 (6) : p 1-7

3. Dong Dazhong, Gao Shikui, Huang Jinliang, etc. A discussion on the shale gas exploration \& development prospect in the Sichuan Basin (Chinese:Natural Gas Industry) 2014, 34 (12) : p 115

4. Yang Yuanping. A Study of Shale Gas Resources Potential of the Upper Triassic Xujiahe Formation in the Dazhou Region (Chinese:Acta Geologica Sichuan) 2019, 39 (1) : p 72-74

5. Chen Guo, Liu Gehang, Li Hongxi, etc. Resource 
potential of continental shale gas in Upper Triassic Xujiahe Formation,Sichuan Basin (Chinese:Natural Gas Technology and Economy) 2019, 13 (5) : p 2129

6. CJi Youliang, Liu Junlong, Wang Tianyun, etc. Distributing pattern and mapping method of delta and beach-bar composite sand-bodies in continental lacustrine basin (Chinese:Journal of Palaeogeography) 2016, 18 (4) : p 615-630 